\title{
Implications for psychiatric services of chronic civilian strife: young refugees in the UK
}

\author{
Matthew Hodes
}

This is the second in a series of papers on the mental health of marginal groups, including young refugees, homeless children and their families, elderly immigrant populations, prisoners and nurses. The first paper in the series (Tribe, 2002) considers the effects of asylum-seeking and refugee status on mental health.

Over the past century war and organised violence have led to the displacement of large populations and threatened or resulted in genocide of many ethnic or cultural groups. Although many people are internally displaced within their own country, some flee and seek asylum in other countries. The United Nations High Commission on Refugees (UNHCR) defines a refugee as someone who:

'Owing to well-founded fear of being persecuted for reasons of race, religion, nationality, membership of a particular social group or political opinion, is outside the country of his nationality and is unable or, owing to such fear, is unwilling to avail himself of the protection of that country; or who, not having a nationality and being outside that country of his former habitual residence as a result of such events, is unable or, owing to such fear, is unwilling to return to it' (UNHCR, 1951: Article 1A(2)).

UN data (as at 22 June 2002, cited on http:/ / www.unhcr.ch/statistics) indicate that there are over 12 million refugees in the world, nearly 7 million people are internally displaced, and a total of over 19 million are a cause for concern. Until the 1990s most of this population were living in the Middle East and Africa. The Yugoslavian tragedy and other conflicts in eastern Europe have resulted in larger numbers of refugees coming to Western Europe. Currently there are over 7 million refugees, asylumseekers and internally displaced people in Europe.
It has been estimated that over the past 15 years about 300000 refugees/asylum-seekers came to the UK, and about $85 \%$ of these have settled in London (Bardsley \& Storkey, 2000). The Asylum Act 1999, which became effective from April 2000, sought to disperse asylum-seekers from London but in view of the drift of people back to the capital, the effect is unclear. The population of refugees/asylum-seekers is predominantly young, with $40 \%$ under 18 years of age. There are significant numbers of unaccompanied asylum-seeking and refugee children in the UK: in 2001 there were over 6000, mostly living in London and Kent (Refugee Council, 2002).

The asylum-seekers and refugees come from all over the world, but in recent years many have come from the former USSR and Yugoslavia, the Middle East, Afghanistan, sub-Saharan Africa and the Horn of Africa, and South America.

\section{Legal background}

The Asylum Act 1999, together with the 2002 White Paper (Home Office, 2002), will have a significant impact on how asylum-seekers are treated. The White Paper aims to replace the voucher system with cash support, which will help asylum-seekers. It is also intended to develop a more holistic reception and induction process. There will be a three-tier structure.

Tier 1 Induction centres will be established across the UK to replace the current emergency accommodation. Asylum-seekers will make own-

Matthew Hodes is a senior lecturer in child and adolescent psychiatry at Imperial College (Academic Unit of Child and Adolescent Psychiatry, Faculty of Medicine, Imperial College of Science, Technology and Medicine, Norfolk Place, London W2 1PG, UK) and a consultant child and adolescent psychiatrist at St Mary's Department of Child and Adolescent Psychiatry, Central and North-West London Mental Health Trust. In recent years he has been developing research and mental health services for young refugees in the Paddington area of West London. 
language briefings and initial asylum claims. Basic health screening will be provided. It is expected that people (including children) will stay in these centres for up to 1 week.

Tier 2 Four accommodation centres will be piloted across the UK to house people for the full duration of their asylum claim. Each centre will accommodate about 750 people, including children. Legal advice, health care and education will be available. The intention is that people will be in these centres for up to 6 months. Concern has been expressed by the Refugee Council that the institutional nature, segregated educational provision and location of the centres will make them unsuitable for many individuals (Refugee Council, 2002).

Tier 3 Removal centres will be used for people whose asylum application is not successful and who will be deported.

The dispersal policy, which began with the Asylum Act 1999, will continue. This policy is intended to reduce the numbers of asylum-seekers in London. However, its effect may be to reduce the potential for the development of community ties and to increase isolation. There is anecdotal evidence for the drift of families back to London and other metropolitan areas, and this has implications for mental health and family life.

\section{Case example 1}

A boy of 8 years was being treated for post-traumatic stress disorder and depression that occurred following his exposure to war and atrocities in the former Yugoslavia, where his father had been killed. He lived in London with his mother and sister. His maternal grandparents had been living nearby but were rehoused to Liverpool. In view of his grandfather's treatment for physical illness at a local London hospital, and the family's wish to stay together, the grandparents returned to London and stayed with their daughter and grandchildren. This resulted in overcrowding, with the mother and sister sleeping in the front room, and produced obstacles to accessing financial and other support.

\section{Adversities}

People become asylum-seekers and refugees, as described in the UNHCR definition above, because of the experience of or fear of organised violence and persecution. Family members, including children and adolescents, may be imprisoned, tortured or killed, or witness such events. This may result in unplanned departure from home and community, and sometimes hazardous and prolonged journeys in pursuit of safety. Journeys may result in detention of family members and also privation with regard to physical needs such as food and shelter. On arrival in resettlement countries, including European countries, there may be prolonged periods of detention and hardship. In the UK, young asylum-seekers and their families experience social isolation, fear and uncertainty about asylum applications, financial hardships associated with very limited and degrading financial support, homeless accommodation and mobility, linguistic barriers and difficulty accessing services, and racism (Aldous et al, 1999; Hodes \& Goldberg, 2002). Many of these difficulties continue after refugee status (exceptional leave to remain or full refugee status) has been obtained. However, it appears that as time goes by the refugees who can stay in the UK have longer periods in stable accommodation, gradually acquire English-language skills, and children and parents take up educational opportunities. In London and other cosmopolitan towns, social networks are established, with maintenance of cultural and religious identities and practices.

\section{Implications for mental health}

Fuller accounts of the psychiatric implications of young refugees' adverse experiences exist elsewhere (Ahearn \& Athey, 1991; Rousseau, 1995; Sack, 1998; Hodes, 2000), but some of the salient points will be summarised here. In considering the mental health of young refugees in the UK it is important to bear in mind that there is no population-based information available and only extremely limited data resulting from contact with child mental health services. However, there is an accumulating body of epidemiological data from Scandinavia and North America. Many of these studies concern young refugees with similar backgrounds to those who have come to the UK, and so it is reasonable to extrapolate from these findings to the British situation.

Although a high proportion of young refugees in resettlement countries have been exposed to terrible events and great adversity, many appear to cope well despite the stress and suffering that they have experienced. They have good social adjustment and do not have significant psychiatric morbidity. Resilience in children may occur for many reasons, including temperament, coping style, greater commitment to the combatants' own side, and the presence of supportive and harmonious family relationships (Hodes, 2000). Regarding gender, males and females may have significantly different exposure to war and other violence, including rape, which may affect mental health. However, with similar exposure to violence and adverse events there are inconsistent findings with regard to whether gender is protective. 
Age is also an important factor. Clearly, infants are protected by their cognitive immaturity, and their well-being is closely related to that of their carers. For older children, their understanding of events is important, but findings are inconsistent with regard to whether increasing age is protective in coping with adverse experiences.

Nevertheless, the evidence indicates that young refugees are at increased risk, compared with immigrant or indigenous children, for psychological symptoms and psychiatric disorders. Obviously, the rates and kinds of psychiatric disorder within a particular community will depend on the exact adversities to which individuals have been exposed. Very high threat is represented by proximity to and witnessing of the killing of family or community members and experience of torture or imprisonment; less threatening is knowledge of war or organised violence (Espino, 1991; Garbarino \& Kostelny, 1996).

An extreme situation is illustrated by children from Pol Pot concentration camps in Cambodia. A group of 46 school pupils, 40 of whom had been exposed to the horrors of the Pol Pot regime, were assessed after settlement in the USA aged 14-20 years (Kinzie et al, 1986). During their 4 years in the concentration camps most had experienced starvation and separation from family, and almost half had seen people being killed and experienced being beaten. Twenty $(50 \%)$ of the group had posttraumatic stress disorder (PTSD), 5 (12.5\%) had major depression and 16 (40\%) had other affective disorders. Their social adjustment was impaired and was within the clinical range. Twelve years after the initial study, 35\% had PTSD and 14\% had depression (Sack et al, 1999). Although the PTSD is relatively persistent, the depression has diminished significantly, in association with settlement and the development of social ties. These data, revealing the different courses of the disorders, also support the validity of the diagnostic categories.

Clearly, many young refugees have been exposed to less-traumatic events than the Cambodians, and in this regard a study of 50 young Iranian children is relevant (Almquist \& Broberg, 1999). The children left Iran, on average aged 5 years, and settled in Sweden. Most had been exposed to bombardment from missiles or seen assaults on parents. When first seen 12 months after arrival in Sweden only 26\% were regarded as having good psychological adjustment, with only minor or no psychological symptoms. At follow-up 30 months later, 38\% were regarded as having good psychological adjustment; $18 \%$ had severe post-traumatic stress symptoms; and a further $18 \%$ reached the criteria for PTSD. The prevalence of PTSD did not decrease with time. Maternal wellbeing predicted emotional well-being in the children at follow-up, and long-lasting post-traumatic stress symptoms were predicted by degree of exposure to violence and war.

Among children who have largely not been exposed to war, rates of disorder still appear to be significantly higher than in their non-refugee peers. More than 200 adolescents from 35 countries, who were largely not exposed to war and who settled in Montreal, were assessed using structured interview (Tousignant et al, 1999). The rate of psychiatric disorder was 21\% (simple phobia was excluded because of its association with low social impairment), compared with $11 \%$ among a comparison group. Depression and conduct disorder were twice as high in the refugee group and were associated with significant social impairment.

Developmental considerations are important to the way in which young refugees will show their distress (Yule et al, 1999). After frightening experiences children may be distressed and tearful. Most children will be troubled by repetitive, intrusive thoughts and flashbacks. Sleep disturbance, with fears of the dark and bad dreams, may occur. Separation difficulties are frequent, even in teenagers. Younger children may lose skills that they have previously acquired, such as bladder control. Many children show, and their teachers report, difficulties in concentrating and restlessness. There may be associated depressive symptoms and, in adolescents, PTSD is frequently comorbid with depression.

Refugee children may have disorders and difficulties that would have occurred even if they had not been displaced and become refugees. Developmental disorders, including speech and language disorders, specific reading disorder (developmental dyslexia) and ICD-10 'mental retardation', and neuropsychiatric disorders such as psychoses and hyperkinetic disorder may all occur and lead to presentation at services (Howard \& Hodes, 2000).

Individual and family life-cycle issues are also important. Young children may settle quickly in school, learn English more rapidly than their parents and acquire a culturally different peer group, while parents remain unemployed and relatively socially isolated over many years. At the same time, parents may start to depend on their children, so inverting the usual structure of family organisation. Generational differences in values and challenges to traditional family organisation may contribute to conflicts in adolescence.

\section{Universal interventions}

Given that the psychological well-being of children and adolescents is related to family and community 
Table 1 Current social exclusion initiatives for young people

\begin{tabular}{|c|c|c|}
\hline Initiative & Targeted group & Expected outcomes or aims \\
\hline Sure Start & $\begin{array}{l}\text { Children } 0-4 \text { years in } \\
\text { defined geographical areas }\end{array}$ & $\begin{array}{l}\text { Improved learning and emotional adjustment } \\
\text { Improved parenting, reduced family distress } \\
\text { and maternal depression } \\
\text { Improved physical health, including reduction } \\
\text { of children's accidents and injuries } \\
\text { Strengthening of community ties }\end{array}$ \\
\hline Education Action Zones & $\begin{array}{l}\text { Groups of } 15-25 \text { schools } \\
\text { (primary and secondary) }\end{array}$ & $\begin{array}{l}\text { Improved behaviour, fewer school exclusions } \\
\text { Improved scholastic attainment } \\
\text { Innovation in educational system }\end{array}$ \\
\hline Connexions & Youths aged 13-19 years & $\begin{array}{l}\text { Advise and support; promote personal } \\
\text { development }\end{array}$ \\
\hline Youth Offending Teams & $\begin{array}{l}\text { Youngsters aged } 11-17 \text { years } \\
\text { who have offended or are at } \\
\text { risk of offending }\end{array}$ & $\begin{array}{l}\text { Coordinate the provision of youth justice } \\
\text { services, with the overall aim of preventing } \\
\text { offending by children and young people }\end{array}$ \\
\hline Quality Protects & $\begin{array}{l}\text { Looked after children and } \\
\text { those at risk of being } \\
\text { looked after }\end{array}$ & $\begin{array}{l}\text { Reduce family/placement breakdown } \\
\text { Improve life chances and academic achievement } \\
\text { Promote psychological and physical development } \\
\text { Provide support in independent living }\end{array}$ \\
\hline
\end{tabular}

function, it is widely accepted that supporting whole communities will contribute to the promotion of youngsters' psychological adjustment (UNHCR, 1994). This requires financial and legal support while asylum applications are being processed and, ideally, the planning of housing to reduce mobility and the repeated breaking of community ties.

Many agencies have responsibility for promoting the psychological well-being and social adjustment of young refugees. In recent years, the government has made great investment in tackling social exclusion. Initiatives for young people across the span of years from infancy to early adulthood target specific phases of life and those, such as refugees, at high risk of social exclusion. These initiatives are summarised in Table 1. Furthermore, it is expected that there be coordination across agencies and services targeting social exclusion (Department of Health, 2001). This could include cross-funding so that specific initiatives fund child mental health professionals.

Regarding education, schools may need to expand their induction programmes and English-language support for refugee children, who may have had limited or disrupted schooling prior to settlement (Rutter \& Jones, 1998). Some schools with large numbers of refugees will be in Education Action Zones, which have additional resources for improving scholastic attainment and behavioural adjustment.

Local authorities, through social service departments, also have an important role to play, and refugee children, as a vulnerable group, should be considered in the children's service plans. The rights and welfare of unaccompanied asylum-seeking and refugee children are covered by the Children Act
1989 (England and Wales). This includes the requirement to consider their psychological as well as cultural development.

\section{Tiered child and adolescent mental health services}

General principles regarding child and adolescent mental health services (CAMHS) are relevant for young refugees (Harrington et al, 1999). Needs for services may be epidemiologically defined in relation to rates of disorder. They may also be defined in relation to social impairment. In relation to refugee mental health, it is relevant that some studies have shown relatively low levels of social impairment in the presence of disorders such as PTSD (Mollica et al, 1997).

Needs can also be defined in terms of the lack of effective care. Effective care refers to interventions that have demonstrated efficacy on the basis of robust research designs (Harrington et al, 1999). As has been indicated, refugees have high rates of symptoms and disorders such as anxiety and adjustment disorders, PTSD, depression and oppositional-defiant behaviours for which effective treatments are available. In this sense they are likely to have unmet need.

However, refugees come from diverse cultural backgrounds and will vary in the extent to which they perceive that a disorder or symptoms are present and seek help. They also have variable English-language fluency, and there are obstacles 
to registration with general practitioners (GPs) and accessing services. Thus, despite high need, they may vary in the extent to which they express demand for CAMHS. Service development and configuration should therefore take into account epidemiological data regarding rates of disorder and levels of impairment, and provide effective treatments in a context and form that can be used by families.

Given the relatively large numbers of children with psychiatric impairment and relatively scarce resources to manage them a tiered system of care is required. The influential model described in the Health Advisory Service report (1995) advocates a four-tier system.

\section{Tier 1}

Primary care, schools and other community agencies represent the first tier. This tier would deal with most children's minor behavioural difficulties, and anxieties and disorders such as enuresis. Provision for accessing health care such as help with interpreting and registration with a GP has been supported by many health authorities, and provider units have developed community-based projects (Aldous et al, 1999). This work may be carried out in such a way that refugees are specifically targeted, for example by outreach health visitors who visit homeless accommodation such as hotels that have significant numbers of refugees.

Tier 2

Tier 2 refers to solo child mental health professionals in community settings such as schools or health centres, who manage youngsters with troubling symptoms or minor disorders (e.g. adjustment disorders or oppositional-defiant disorder). These professionals also inform Tier 1 professionals about child mental health issues, and facilitate referral of selected children to Tier 3 services.

\section{A Tier 2 service}

Since 1996 an outreach child mental health service has been provided to a junior school (school for children aged 7-11 years) in Paddington, west London, an area with many refugees. The background to the project is described in more detail elsewhere (O'Shea et al, 2000). Further data are now available (details available from the author upon request) and, despite methodological problems affecting the study, these are given here in view of the absence of other published intervention studies. One weekly session has been provided in the school by different professionals, initially a family therapist, then a specialist registrar in child psychiatry and finally a behavioural nurse therapist. Teachers in the school identify psychologically distressed children, fill in a form regarding basic information and complete the Strengths and Difficulties Questionnaire (SDQ; Goodman, 1997). They discuss their concerns with the special educational needs coordinator, who liaises with the child mental health professional. There would then be further consultation with the teacher and/or meetings with the child and family/carers.

In all, 30 children were referred to the service. These were 25 boys and 5 girls, with a mean age of 9.7 (s.d. $=0.92)$ years. They came from diverse regions and had many different languages: 15 from the Middle East (8 Arabic, 7 Kurdish speakers), 6 from sub-Saharan Africa (3 Somali and 3 other languages), 6 from Europe (5 spoke Albanian, 1 Serbo-Croat), 3 from South America (all Spanish speakers). They had been in the UK for a mean of 2.8 years (s.d. $=1.9) ; 28$ were known to be living with at least one family member and 16 were regarded as living in overcrowded accommodation. Sixteen had a clear history of separation from at least one close family member and 17 were known to have had exposure to war and violence. For 15 of the children, the carer was regarded as having a mental health problem, but only two were receiving psychiatric help. Clinical and treatment information is summarised in Table 2.

Table 2 Clinical and treatment data for the 30 children referred to a school-based refugee mental health service

Interpreter needed for assessment/therapy, $n$

Yes

No

Missing

ICD-10 diagnostic category, $n$

Mood, adjustment or anxiety disorder 9

Behavioural disorder/hyperkinetic disorder

Disorder of scholastic skills/speech development

Combination of the above categories

No disorder, has symptoms

Unclear/missing data

Type of treatment offered, $n$

Family sessions

Group for children

Treatment uptake, $n$

Did not engage, i.e. did not start treatment 3

Premature drop-out

Negotiated discharge with recovery

Negotiated discharge without full recovery 6

Referral to specialist Tier 3 service

No. of treatment sessions, ${ }^{1}$ mean (s.d.)

$9.0(6.3)$

Teachers' Strengths and Difficulties scores

At initial assessment ${ }^{2}$

Change in score ${ }^{3}$ between initial assessment and outcome after intervention

Outcome at end of intervention

1. Includes those who drop-out (data available on 21)

2. Data available on 28.

3. Data available on 18 
Regarding the effectiveness of the intervention, there was a trend towards improvement in the SDQ score $(t=1.93, P=0.071)$; the failure to achieve significance at the 0.05 level was probably attributable to the small sample size. These data include a small number of children who became more disturbed because their families' asylum application was unsuccessful and they would soon have to leave the UK. The reductions in SDQ scores were the same size as those observed in children attending Tier 3 services (Garralda et al, 2000). There was positive feedback about the service from teachers and families.

\section{Tier 3}

Tier 3 services are multi-disciplinary CAMH teams that are expected to manage youngsters with severe and complex problems, who have high levels of comorbidity with greater social impairment and more complex family and social situations. Concerns have been expressed about whether young refugees would attend Tier 3 services, but impressions from many child mental health professionals are that they do access them. Study of attendees at our Tier 3 clinical department in Paddington, west London found that, compared with immigrant and also White British controls, the refugees tended to have more psychosocial disorders (e.g. depression, PTSD) and fewer neuropsychiatric disorders, but they had similar levels of social impairment (Howard \& Hodes, 2000). As expected, the refugees had experienced greater levels of past and ongoing adversities, including family isolation, than the other groups. The refugees were more likely to be referred by community agencies such as social workers and schools and less likely to be referred by doctors (GPs and paediatricians). Despite a far greater involvement of interpreters and the ongoing social and economic difficulties, the refugees were no more likely to drop out of treatment prematurely. The implications of this study are that Tier 3 services have an important role to play in addressing the mental health needs of young refugees with more severe psychiatric problems. Since they will attend regularly and make good use of the services, but have a high need for interpreters, there are substantial resource implications. The following case vignette is illustrative of the work that may be carried out in Tier 3 settings.

\section{Case example 2}

A 12-year-old girl was referred by her GP because of loss of appetite and nightmares. She came from the former Yugoslavia, where her father had been on a 'list' for detention for many years. When she was 10 years old, because of the war and believing that they would be killed, she and her family had to flee to the forest, where over a 6-week period she heard gunfire and saw dead bodies. In the initial assessment interviews she described nightmares, high arousal and anxiety symptoms, and feeling scared when her family were not close. In addition, at night she would check twice that the front door was closed and she had hand-washing rituals. She had avoidance of many foods such as milk and beef, fearing that they were contaminated, and low weight. She reached the diagnostic criteria for PTSD and comorbid obsessivecompulsive disorder. Treatment along cognitivebehavioural lines, which involved exposure with family involvement to increase her eating and reduce dependence on her family, was offered and she has shown substantial improvement. All sessions were carried out with one of her older siblings, who seemed to have a rota to attend with her in the absence of the parents, who would not attend regularly. An interpreter was required for the sessions. During the course of treatment the family were rehoused to a distant part of London, which made attendance more difficult.

\section{Tier 4}

This tier refers to highly specialised out- or inpatient services that are supralocal and serve large populations. Only small numbers of young refugees need psychiatric admission. In a recent study (further details available from the author upon request) of London's adolescents who required psychiatric admissions I found that young refugees were overrepresented. They are as likely as other adolescents to be admitted because of psychoses. In addition, there are specific issues for refugees, such as the experience of losses and stressful events, that may be related to deliberate self-harm and aggressive outbursts. Language and cultural differences can complicate the assessment of social functioning, and disrupted schooling may render learning difficulties harder to manage. There may be a background of separated and fragmented families, parenting difficulties and parental mental health problems related to experience of loss, torture and abuse. These factors may make it hard to work with families in the usual way, i.e. expecting them to actively support admission and discharge planning. Obviously, a high level of multi-agency collaboration is needed for the management of these situations.

\section{The voluntary sector}

The non-statutory sector includes two kinds of service. First, there are the community networks and self-help that refugees themselves provide. They may involve 
doctors and other professionals, who can use their skills in this context. There are interesting accounts of how such services have developed (Dihour \& Pelosi, 1989). Although all communities have such networks of help, a special feature among refugees is their relatively high level of isolation, especially among those newly arrived. A complicating factor is that contact with people from their cultural group may not always be welcomed because of complex political alliances and fears about confidentiality.

Second, there is the well-known Medical Foundation for the Victims of Torture. This organisation, situated in north London, has established itself because of its pioneering provision and expertise in offering psychiatric treatments, as well as medical assessments and medico-legal help, to asylumseekers and refugees when many mental health trusts did little to take on this work. The Foundation has for a number of years received referrals of young people and their families and provided family therapy and psychoanalytically oriented treatments. In recent years, other refugee counselling services have been developed in the voluntary sector.

The problems and qualities of voluntary and independent providers have been described by Bhui et al (2000) and are summarised in Table 3.

\section{Treatment considerations}

Many general aspects of treatment are as relevant for work with refugees as with non-refugees. It is important for the therapist to adopt an empathic and flexible stance, and provide treatments that are congruent with families' culturally informed models of psychological distress and healing. In view of the varied psychiatric disorders and problems that refugees may present to $\mathrm{CAMH}$ professionals the full range of treatments will be needed, and where possible these should be provided using evidencebased principles (Harrington et al, 1999).

However, some refugee experiences are specific and may influence assessment and treatment. First, attending for interviews and therapy, with the disclosure that is required, may remind some families of past experiences such as interrogation, torture or war, and heighten anxiety. Over time, as treatment progresses and trust in the therapist increases, these fears may diminish. For other families, seeing therapists from a different culture may be reassuring, and occasionally families choose to avoid an interpreter because of fears over confidentiality and for political reasons.

A second issue is the variable extent to which families and young people are able to recount their experience of survival and adversity (Papadopoulos, 1999). Some families are very quick to share their harrowing accounts of war and explain the child's and family's suffering in terms of the past. Others, however, want to look forward and avoid considering events and losses of the past, which are felt to be unchangeable. These families prefer to deal with their children's behaviour and current problems with school and housing. In general, it is important to respect the families' views, and this may require restraint by therapists who wish to explore past events, which are perceived to be the most significant aetiological factors for distress and disorder.

The third aspect of work with refugees is the need to take a flexible 'advocacy' role and provide help for the family. Requests for support for important practical issues (e.g. housing transfer, help with education and requests for psychiatric reports for asylum applications) are frequent. Another example of flexibility is the need for CAMH professionals to be aware of parental mental health problems and the importance of liaison with GPs and adult mental health teams to ensure that appropriate treatment is provided.

\section{Conclusions}

Many refugees have experienced significant adversities which are risk factors for psychiatric disorders and symptoms in children and parents. Helping refugees to settle requires community and

Table 3 Problems and qualities of voluntary and independent providers (after Bhui et al, 2000)

Problems

Limited funding, services often not sustainable Marginalised, limited influence

Poor management, lack of experience of service evaluation

Poor clinical governance: audit, risk management, professional skills development
Qualities

Smaller, more informal and personal service

Cultural knowledge, appropriate ways of relating to people, appropriate models of therapy

Linguistic competence where English is not the first language

Flexible working patterns 
multi-agency planning of services. Young refugees may benefit from targeted community-based mental health services, which may be in the statutory or voluntary sector. Some will require referral to Tier 3 specialist CAMH teams. Research information regarding young refugees' mental health and service provision is generally lacking. The optimal service configuration, including the balance of community and Tier 3 services, and the possibility of more integrated child and adult refugee mental health services should be further investigated. Service configuration across the UK may need to vary because of differences in the numbers of refugees in each area.

\section{References}

Ahearn, F. \& Athey, J. L. (1991) Refugee Children. Theory, Research and Services. Baltimore, MD: Johns Hopkins University Press.

Aldous, J., Bardsley, M., Daniell, R., et al (1999) Refugee Health in London. Key Issues for Public Health. London: East London \& The City Health Authority.

Almquist, K. \& Broberg, A. G. (1999) Mental health and social adjustment in young refugee children $3 \frac{1}{2} 2$ years after their arrival in Sweden. Journal of the American Academy of Child and Adolescent Psychiatry, 38, 723-730.

Bardsley, M. \& Storkey, M. (2000) Estimating the numbers of refugees in London. Journal of Public Health Medicine, 22, 406-412.

Bhui, K., Bhugra, D. \& McKenzie, K. (2000) Specialist Services for Minority Ethnic Groups? Maudsley Discussion Paper No. 8. London: University of London, Institute of Psychiatry.

Department of Health (2001) Coordinated Service Planning for Vulnerable Children and Young People in England. London: Department of Health.

Dihour, O. E. \& Pelosi, A. J. (1989) The work of the Somali Counselling Project in the UK. Psychiatric Bulletin, 13, 619-621.

Espino, C. M. (1991) Trauma and adaptation: the case of Central American children. In Refugee children. Theory, Research and Services (eds F. Ahearn \& J. L. Athey), pp. 106-124. Baltimore, MD: Johns Hopkins University Press.

Garbarino, J. \& Kostelny, K. (1996) The effects of political violence on Palestinian children's behavior problems: a risk accumulation model. Child Development, 67, 33-45.

Garralda, M. E., Yates, P. \& Higginson, I. (2000) Child and adolescent mental health service use. HoNOSCA as an outcome measure. British Journal of Psychiatry, 177, 52-58.

Goodman, R. (1997) The strengths and difficulties questionnaire: a research note. Journal of Child Psychology and Psychiatry, 38, 581-586.

Harrington, R. C., Kerfoot, M. \& Verduyn, C. (1999) Developing needs-led child and adolescent mental health services: issues and prospects. European Child and Adolescent Psychiatry, 8, 1-10.

Health Advisory Service (1995) Child and Adolescent Mental Health Services. Together We Stand. London: HMSO.

Hodes, M. (2000) Psychologically distressed refugee children in the United Kingdom. Child Psychology and Psychiatry Review, 5, 57-68.

— \& Goldberg, D. (2002) The treatment of refugees: service provision reflects Britain's ambivalence. Psychiatric Bulletin, 26, 1-2.

Home Office (2002) Secure Borders, Safe Haven. Integration with Diversity in Modern Britain. Cm5387. Norwich: Stationery Office.

Howard, M. R. \& Hodes, M. (2000) Psychopathology, adversity and service utilisation of young refugees. Journal of the American Academy of Child and Adolescent Psychiatry, 39, 368-377.
Kinzie, J. D., Sack, W. H., Angell, R. H., et al (1986) The psychiatric effects of massive trauma on Cambodian children: I. The children. Journal of the American Academy of Child Psychiatry, 25, 370-376.

Mollica, R. F., Poole, C., Son, L., et al (1997) Effects of war trauma on Cambodian refugee adolescents' functional health and mental health status. Journal of the American Academy of Child and Adolescent Psychiatry, 36, 1098-1106.

O'Shea, B., Hodes, M., Down, G., et al (2000) A school based mental health service for refugee children. Clinical Child Psychology and Psychiatry, 5, 189-201.

Papadopoulos, R. (1999) Working with Bosnian medical evacuees and their families: therapeutic dilemmas. Clinical Child Psychology and Psychiatry, 4, 107-120.

Refugee Council (2001) Where are the Children? A Mapping Exercise on Numbers of Unaccompanied Asylum-Seeking Children in the UK: September 2000-March 2001. London: Refugee Council \& British Agencies for Adoption and Fostering.

- (2002) Asylum-Seeker Accommodation Process. Refugee Council Proposal for a Community-Based Pilot. London: Refugee Council.

Rousseau, C. (1995) The mental health of refugee children. Transcultural Psychiatric Research Review, 32, 299-331.

Rutter, J. \& Jones, C. (1998) Refugee Education. Stoke on Trent: Trentham Books.

Sack, W. (1998) Multiple forms of stress in refugee and immigrant children. Child and Adolescent Psychiatric Clinics of North America, 7, 153-167.

-, Him, C. \& Dickason, D. (1999) Twelve-year follow-up study of Khmer youths who suffered massive war trauma as children. Journal of the American Academy of Child and Adolescent Psychiatry, 38, 1173-1179.

Tousignant, M., Habimana, E., Biron, C., et al (1999) The Quebec adolescent refugee project: psychopathology and family variables in a sample from 35 nations. Journal of the American Academy of Child and Adolescent Psychiatry, 38, $1426-1432$.

Tribe, R. (2002) Mental health of refugees and asylumseekers. Advances in Psychiatric Treatment, 8, 240-248.

United Nations High Commission on Refugees (1951) The 1951 Refugee Convention. Geneva: UNHCR.

- (1994) Refugee Children. Guidelines on Protection and Care. Geneva: UNHCR.

Yule, W., Perrin, S. \& Smith, P. (1999) Post-traumatic stress reactions in children and adolescents. In Post-Traumatic Stress Disorders (ed W. Yule), pp. 25-50. Chichester: John Wiley \& Sons.

\section{Multiple choice questions}

1. Regarding the numbers of refugees:

a most of the world's refugees and internally displaced people live in Europe

b there are currently probably fewer than 250000 refugees in the UK

c about $20 \%$ of the refugees in the UK are under 18 years old

$\mathrm{d}$ in London there are currently just over 4000 unaccompanied refugee children for whom the local authorities have some responsibility

e the Asylum Act 1999 will distribute refugees into communities of equal size across the UK.

2. Regarding the psychological consequences for young people of exposure to war and violence:

a proximity to the events is far more important than the individual child's resilience 
b boys and girls may have had different exposure to the events

c young children cannot have PTSD

d psychological reactions to traumatic events may vary according to developmental stage

e adolescents with PTSD will grow out of it.

3. The psychological well-being and social adjustment of young refugees:

a are mainly the responsibility of the NHS

$\mathrm{b}$ cannot be considered in relation to the Children Act 1989 (England and Wales)

c are not considered in recent social exclusion initiatives

$\mathrm{d}$ are helped by all government policies and laws

e probably improve spontaneously over time.

4. Young refugees:

a in view of the obstacles to referral, have greater social impairment when seen at Tier 3 clinics than non-refugees

b cannot access Tier 3 CAMHS

c are known to have higher rates of drop-out from Tier 3 services than immigrant or British comparison groups

d will not be referred by GPs and paediatricians e who attend Tier 3 clinics probably cannot be helped if interpreters are needed.

5. Regarding service provision and psychiatric treatments for young refugees:

a the voluntary sector does not contribute

b the evidence base may influence the choice of effective treatments

c attending for treatment is always initially associated with reduction of anxiety and distress

$\mathrm{d}$ individual psychological treatments are always the treatments of choice

e recounting past traumatic events is a requirement for treatment.

MCQ answers

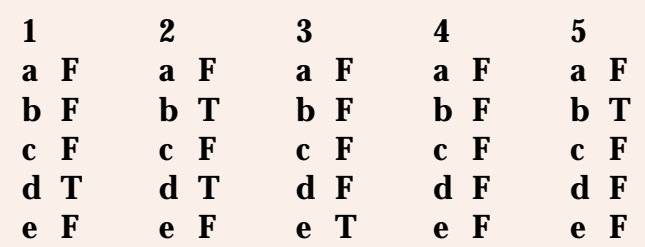

\section{Commentary}

\section{Gordana Milavic}

This commentary has been written after the World Trade Centre disaster in the USA and during an almost palpable re-examination of many of our values, particularly those related to the question of asylum-seekers, refugees and immigrants. In a new world order, where words such as war and civilian strife become imponderable, where it is near impossible at first glance to make out friend from enemy, how will societies be certain who is and who is not a refugee, and find the ability at the same time to respond to their increasing numbers? As new refugee camps around the world are set up and are swollen by thousands, as ships carrying asylum-seekers are denied docking, a political and social debate has been rekindled. What effect are these new policies, bills and guidelines likely to

Gordana Milavic is a consultant child and adolescent psychiatrist and the Clinical Director of the Child and Adolescent Mental Health Services of Oxleas NHS Trust in south-east London (Highpoint House, Memorial Hospital, Shooters Hill, London SE18 3RZ, UK). She has clinical and field experience in working with refugee children and young people, being particularly interested in the study of psychological trauma. 